\title{
The Monolingual Lusoga Dictionary Faced with Demands from a New User Category
}

Minah Nabirye, Department of African Languages and Cultures, Ghent University, Belgium; Institute of Languages, Makerere University, Kampala, Uganda; and Menha Publishers, Kampala, Uganda (mnabirye@gmail.com), and

Gilles-Maurice de Schryver, Department of African Languages and Cultures, Ghent University, Belgium; Xhosa Department, University of the Western Cape, Bellville, South Africa; and TshwaneDJe HLT, Stellenbosch, South Africa (gillesmaurice.deschryver@UGent.be)

\begin{abstract}
In this article, a case is presented of an existing dictionary that is aimed at users with a minimum of primary 7 education, now faced with demands from users in primary $1-3$. The reason for this demand is the result of the fact that Lusoga is currently being implemented as a medium of instruction in Uganda, in an environment where there is hardly any literature to serve the intended purpose. A review of the existing literature in and on Lusoga shows that the monolingual Lusoga dictionary - Eiwanika ly'Olusoga (WSG) - is the only reference work with essential information, in Lusoga, that can initiate the teaching of Lusoga at the elementary level. Although the information in the WSG may fit the purpose at hand, that information is mainly presented as a summary, with statements of conclusions only. Explanations to ease its access to the new user are thus missing. Findings from a pilot study conducted by the National Curriculum Development Centre on the implementation of the teaching of Lusoga reveal that the new user is not only the primary 1-3 pupil, but also the teacher who will need to instruct that pupil. Since children's literature requires additional consideration beyond what can be presently availed, and since the WSG was actually compiled for an advanced user, the focus is shifted from the primary 1-3 pupil to the primary teacher. For that teacher, it is suggested to compile an additional Guide, expanding on the various extra-matter texts and especially the Language Portrait found in the WSG. This is done on the assumption that once the information is expanded and re-represented, a teacher will be able to combine the information in the Guide with that in the WSG, in order to make a Lusoga syllabus from which to draft Lusoga lessons. Although the ideal would of course be to be able to produce fully-fledged customised primers from scratch, this article's main argument is that in the absence of both human and financial resources to do so, one can reuse and expand on the data found in an existing higher-level dictionary.
\end{abstract}

Keywords: LANGUAGE POLICY, MOTHER-TONGUE EDUCATION, LUSOGA, UGANDA, PRIMER, SYLLABUS, GUIDE, ELEMENTARY USER, PRIMARY TEACHER, TEACHER TRAINING, ORTHOGRAPHY, GRAMMAR, LINGUISTIC INFORMATION, MONOLINGUAL DICTIONARY, EXTRA-MATTER TEXTS, LANGUAGE PORTRAIT, PICTORIAL ILLUSTRATIONS 
Obufunze: Eiwanika ly'Olusoga lizuuseeku omukozesa ataali muluubilile. $\mathrm{Mu}$ lupapula muno mulagibwamu engeli Eiwanika ly'Olusoga elyawandiikilwa omukozesa atuuseeku mu kyomusanvu bwe lizuuseeku omukozesa okuva mu kibiina kyolubelyebelye okutuuka mu kyokusatu. Kino kiidhie lwa kuba ensomesa y'olulimi Olusoga eli kuteebwa mu nkola aye ng'ebyetaagisa okutuukiliza omulimu guno bikaali kutuukilizibwa. Okwekeenenia kw'ebiwandiiko ebiliwo ku oba mu Lusoga ebisobola okwemelezaawo ensomesa mu lulimi Olusoga kuzwile nti Eiwanika ni lyonka elilina ebyetaagibwa okusimba omusingi gw'ebyendhegelesa mu lulimi Olusoga ebisobola okutuukana n'ebyetaago by'omukozesa aluubililwa mu kiseela kino. Waile ng'amakobo g'Eiwanika gaaliba gatuukana n'ebyetaago by'omukozesa ono, engeli ye gaategekebwa mu Iwanika teyanguyila mukozesa ono muyaaka kugeeyunila bukalamu. Okwinhonhola kw'amakobo g'Eiwanika kwasinga kukolebwa mu musomo amakobo gano mwegaasibuka. Kale kyaba nti amakobo agandi gazila bulungi businziilo mu Iwanika busobola kwetengelela kuyamba omukozesa aluubililwa. Ebyava mu kugezesa ensomesa y'ebyennnimi enzaalilanwa mu Uganda okwakolebwa ekitongole kya National Curriculum Development Centre byazuula nti omusomi ti ni yenka ayenda okutendekebwa aye n'omusomesa agya akusomesa yeena ayenda obuyambi. Engeli ebiwandiiko by'abaana abato bwe by'ekengelwa einho ate ng'omukozesa omuluubilile ow'Eiwanika yali muntu mukulu, eisila lili ku musomesa w'abasomi abo. Okutendeka omusomesa ono mu bimwetaagibwamu ng'asomesa Olusoga, akatabo akandi akalaga engeli y'okusomesaamu amakobo g'Eiwanika kaidha kuwandiikibwa okumulaga engeli y'ayinza okukozesa ebili mu nnhandhula ni mu nfaanana y'olulimi mu Iwanika okutegeka amasomo g'Olusoga ag'endhawulo. Waile nga kyali gwaine nti ebitabo ebita eisila ku nsomesa y'Olusoga mu pulaimale n'ebyalisinze kwetaagibwa, olupapula luno lusinziile ku mbeela eliwo buti ey'eibula ly'ensako n'abakugu abanoonheleza ku Lusoga, n'okusalawo okukozesa ekiwandiiko ekiliwo mu kiseela kino okugaziya emigaso gya kyo eli okutembeeta ensomesa y'olulimi Olusoga ng'esinziilwa ku Iwanika.

Ebigambo ebikulu: EITEEKA LY'EBYENNIMI, ENDHEGELESA Y'ENNIMI ENZAALILANWA, OLUSOGA, UGANDA, ENTEGEKA Y'AMASOMO, OMUKOZESA WA P1-P3, OMUSOMESA WA PULAIMALE, ENTENDEKA Y'ABASOMESA BA PULAIMALE, WALIFU, GULAAMA, AMAKOBO GA KANALULIMI, EIWANIKA LY'OLULIMI OLULALA, EBIWANDIIKO BY'OMU BIKUGILO, ENFAANANA Y'OLULIMI, EBIFAANANI

\section{Language policy vs. reality in Uganda}

Lusoga is an eastern interlacustrine Bantu language spoken in Busoga, Uganda, by slightly over 2 million Basoga. The Basoga are the third-largest ethnic group in Uganda, following the Baganda and Banyankore (UBS 2006: 23). Lusoga is poorly documented and the Basoga have never studied their language. To this day the Basoga have thus never learned to read or write Lusoga. Lusoga is still categorized as an oral language.

The role of Lusoga as a medium of instruction in the region was compromised by the language policies passed in Uganda. For instance, the 1944 Makerere Conference on Language in Uganda chose Luganda as the medium of instruction in Busoga for the primary level, and in 1965 English was introduced as a subject in primary for the whole of Uganda (Ladefoged et al. 1972: 87-99). Lusoga was not considered as a medium of instruction until, in September 
2005, the Ugandan Parliament passed the teaching of Lusoga as one of the nine regional indigenous languages (NCDC 2006: 5). These nine regional indigenous languages include five Bantu languages: Runyoro-Rutooro (JE11-12), Runyankore-Rukiga (JE13-14), Luganda (JE15), Lusoga (JE16), and Rukonjo (JD42); as well Sudanic and Nilotic languages: Lugbara (Central Sudanic), Acholi (Western Nilotic), Ateso (Eastern Nilotic), and Karamojong (Eastern Nilotic) - cf. $\operatorname{NCDC}($ 2006a: 5).

Mother-tongue education in Uganda is currently being implemented in lower primary (P1-P3) - that is, for the first three years of schooling - in spite of not having the required environment to achieve the envisaged goals effectively. For instance: Lusoga, which has featured in the language policy as a medium of instruction in the Busoga region for five years now, has a shortage of qualified mother-tongue teachers as well as a shortage of reference materials needed to sustain its new status. To the best of our knowledge, to date only one elementary primer for the first year (P1) has been compiled in Lusoga, the booklet Idha Tusome 'Come and We Read' by Wambi and Naigaga (2005). Material that can be used throughout primary education, that is the first three years of lower primary (P1-P3) and the next four years of upper primary (P4-P7), is non-existent. Within the current language-policy framework one could argue that material for P4-P7 is not (yet) required, but material for P1-P3 is.

One other monolingual reference work, the Eiwanika ly'Olusoga 'A Dictionary of Lusoga' (WSG, Nabirye 2009) exists, but it was conceived for a target user group with a minimum of P7 education: thus to be used from the last year of primary, through to secondary (both the ordinary "O" level (S1-S4) and advanced "A" level (S5-S6)), and onwards as need arises. ${ }^{1}$ Looking back at the information provided in the WSG, one notices that it actually contains the information needed to facilitate the teaching of Lusoga in lower primary. Since the WSG was compiled for a more mature user, however, this article presents the predicament of the WSG which is currently facing genuine demands from a user not initially targeted.

\section{The Lusoga literature currently available}

Although the documentation of Lusoga has picked up since about a decade ago, there is still very little available. Most of the literature currently available on the local market is characterized as being peripheral. Such literature is thus considered inadequate to handle the formal demands for teaching Lusoga. At the other end, the few comprehensive and scholarly forms of Lusoga literature that exist are not readily available locally, too general and theoretical, and too advanced to serve the needs of the user who currently needs attention. The available literature may be grouped into the four categories discussed below.

The first category consists of so-called Lusoga 'grammars' (Babyale 1999, Korse 1999), booklets on Lusoga orthography (Kajolya 1990, LULANDA and CRC 2004), and Lusoga wordlists (Korse 1999a, Gonza 2007). Babyale (1999) 
was undergraduate research with very basic descriptions of Lusoga. Korse (1999), on the other hand, was compiled by a non-linguist interested in enabling the pedestrian understanding of Lusoga. There does not seem to be a logical selection of the coverage and the 'grammar' is not coherent. The existing booklets on Lusoga orthography - Kajolya (1990), which is actually a revision of the much older Byandala (1963), and LULANDA and CRC (2004) - were found to be inconsistent in their description of the Lusoga orthography. The 2004 orthography, however, has the advantage that it is mostly written in Lusoga. Up until the publication of the WSG, only two wordlists had been available, both with glosses in English: Korse (1999a) and Gonza (2007), with the latter basically a reprint of the former.

The material from this first category cannot be used as reliable references for a monolingual user because this literature is largely bilingual, aimed at a bilingual user. This type of literature serves users who know English and Lusoga and bars the lower primary users from accessing it because (a) this audience does not speak the second language in addition to Lusoga, and (b) a review of the existing Lusoga literature conducted in Nabirye (2008) revealed that most of this locally-produced Lusoga literature had a very shallow coverage. For these reasons, the literature in this first category is not appropriate to teach Lusoga as a mother tongue in lower primary.

In the second category are studies in which Lusoga is featured almost coincidentally. These studies include surveys of the interlacustrine Bantu languages, where Lusoga is typically mentioned only in comparison with other Bantu languages (e.g. Tucker and Bryan 1957, Matovu 1992, Schoenbrun 1997, Matovu and Walusimbi 2000). ${ }^{2}$ In most cases, the descriptions of Lusoga are generalized with a few isolated examples only in Lusoga. These studies provide findings that benefit advanced learners of Bantu languages as well as comparative and historical linguists.

The third category contains studies devoted to the description of Lusoga proper. These include three MA dissertations that are entirely dedicated to Lusoga - two of which were produced at Leyden University, in the Netherlands: Steeman (2001), in which a Lusoga play is interlinearized, and Van der Wal (2004), on Lusoga phonology. The third was produced at Makerere University, in Uganda: Nabirye (2008), in which Lusoga lexicography is described. Four scientific articles on Lusoga appeared in addition, namely Yukawa (2000), Nabirye (2009a), Nabirye (2009b), and De Schryver and Nabirye (2010). Although these studies exist, their presence is not yet fully appreciated because Lusoga is not yet used at the level on which such literature is required.

In the fourth category is literature mostly intended for the monolingual Lusoga audience at large. Works in this category include the New Testament in Lusoga (BSU 1998), ${ }^{3}$ around a dozen Lusoga story books (Lyavala-Lwanga 1967, 1969, CRC 1998, 1999, 1999a, 1999b, 1999c, 1999d, 1999e, 1999f, 1999g, 2000, 2000a, 2002, 2003), a unified orthography (Namyalo et al. 2008), and the WSG. The New Testament and the story books do not really guide the study of 
Lusoga because they do not consider any Lusoga language descriptions. These works can however be utilized in addition to more specialized language-teaching material and guide towards the practice of correct grammatical structures and authentic language use. Namyalo et al. (2008) provides information about the standard writing system for Lusoga. ${ }^{4}$ Lastly, the WSG being the first explanatory dictionary for Lusoga, this meant that it specified foundational language information in Lusoga for the very first time in order to complete the relevant lexicographical tasks. As it turns out, this is the type of information presently required for the formalization of Lusoga as a medium of instruction.

References in categories 1-3 have handled selective descriptions of Lusoga for bilingual audiences or addressed advanced learners, and have neither specified the most basic but essential language content nor its relevant formalized terminology in Lusoga. Lusoga teachers for primary and secondary schools who have to use Lusoga as the medium of instruction find it virtually impossible to successfully carry out their job with the literature mentioned in categories 1-3. Moreover, primary teachers will obviously find it very difficult to read through and formulate a Lusoga syllabus from all the resources that do not specify Lusoga language content and the respective terminology needed to facilitate their lessons.

We can conclude from this overview that the specification of the structure of Lusoga has not yet been given independent scrutiny. Namyalo et al. (2008) and the WSG are the two references that have information that can be directly utilized for purposes of teaching the Lusoga language, in Lusoga, in lower primary. This is so because both of these references provide essential information regarding the structure of Lusoga, information which is needed for the instruction of Lusoga in formal settings. However, Namyalo et al. (2008) has the shortcoming that the metalanguage is English, making it difficult for monolingual users to access. The WSG thus stands out as an ideal Lusoga reference because it specifies all its information in the language of the user. The WSG, then, seems to be the only reference currently available which provides some of the most basic types of information about the structure of Lusoga, information that can serve the purpose of teaching Lusoga to mother-tongue audiences. We will now move on to see the kind of information types described in the WSG that can sustain the study of Lusoga at an elementary level.

\section{Language information specified in the WSG}

In the few studies prior to Namyalo et al. (2008) that handled the rules of spelling in Lusoga, gaps existed. For instance, the specification of full word forms and the different types of words in Lusoga had not yet been established. This made it difficult to demarcate parts of words and consequently hampered the specification of the right spellings. The writing of complex words (i.e. the writing of compounds) and words of foreign origin was problematic too, mainly because the existing orthographies at the time lacked the ability to cater 
for some of the irregularities that arose in their specification. The alphabet was found to be unjustifiably restricted.

The WSG set out to describe the letters of the Lusoga alphabet, with justifications for the new additions, to provide a basis for the writing system of Lusoga. Findings from this research on the specification of the Lusoga alphabet and rules of writing were subsequently tabled in the process of harmonizing the orthography for eastern interlacustrine languages in Uganda and published as Namyalo et al. (2008).

Spelling was also addressed when deciding on the citation forms to be used in the WSG. The research on the morphology of Lusoga led to the formulation of citation styles different from the citation styles found in earlier monolingual Bantu dictionaries. In order to apply the new citation style which uses full word forms (cf. Nabirye 2008, Nabirye 2009a, Nabirye 2009b), ${ }^{5}$ words falling in the verb category especially, were further segmented down to their smallest meaningful parts (morphemes) within the entry. All types of entries and entry styles were described and explained in the front matter of the WSG. These two methods (full words and word segmentation at the lemma level) paved the way for the specification of the Lusoga orthography currently in use.

The second major undertaking for the WSG was the allocation of parts of speech to over 12000 entries. Although both Korse (1999a) and Gonza (2007) are bilingual bidirectional English-Lusoga wordlists, with the word 'dictionary' misleadingly in their titles, they only allocated parts of speech to some of the English lemmas, but not to any of the Lusoga lemmas. See Addenda 1-3.

Neither the Lusoga terms for the different word classes nor a list of Lusoga words with word-class indications existed in the previous references for Lusoga. Specification of this information was therefore pioneered in the WSG. A list of all the word classes that were coined for Lusoga is given and illustrated in the front matter of the WSG, and all the lemmas in the WSG carry a part-of-speech label. See Addenda 4-5.

The WSG also allocated gender to Lusoga nouns and perfective forms to verbs, with a special treatment for irregular forms. All irregular forms were entered and cross-referenced to the entries from which they are derived. In some cases, irregular class genders were written out in full and included with the respective entries to help highlight such forms for the user. Treatment of this nature was also extended to compounded noun forms which are a result of gemination or sound-change rules. Users were either given the derived forms or the canonical forms with a cross-reference to the relevant base entries. Examples of irregular entries are given below (with cl. = class).

(a) (a)kadaada type of bird (a)kagina lice egg l. $\quad[12 / 14,9$ (e)ndaada $]$ cl. 12 \& 9: type of bird / cl. 14: type of birds

l. $\quad[12 / 14,3$ (o)mugina] cl. 12: lice egg / cl. 14: lice eggs, cl. 3: collection of lice eggs 

(b) Kyabazinga
l. [1/2 Bakyabazinga]
King kyapati type of food
(c) (o)ku.b.a to be cl. 1: King /cl. 2: Kings
l. [9/10 dhikyapati]
(o)ku.biiw.a cl. 9: type of food / cl. 10: type of foods
t. [-baile]
(d) nnonze
I have picked
(e)mpya
courtyards
(e) (e)mmamba
meat
(e)nnunga
black ant 9 black ant
small black ant
was
went/became bad
kt. Bona: (o)ku.lond.a
See: to pick
l. Bona: (o)luya
See: courtyard
l. $\quad[9 /-, 12$ (a)kabamba]
cl. 9: meat, cl. 12: small piece of meat
l. $\quad[9 / 10,12(a)$ kalunga $]$

Specification of the concepts for the most common and useful grammatical and linguistic terms in Lusoga was also one of the tasks undertaken in the WSG for the very first time. The terms specified include: Lusoga words for punctuation marks (i.e. full stop, question mark, quotation mark, etc.), parts of speech (i.e. noun, verb, etc.), linguistics terms (i.e. morphology, syntax, etc.), grammatical terms (i.e. gender, aspect, mood, affixes, enclitics, etc.), usage labels (i.e. argot, ameliorative, literal, private, etc.), and symbols (i.e. backslash, asterisk, etc.). The contribution rendered to a language by specifying information of this nature may seem trivial, especially in well-documented languages, but this information did not exist for Lusoga and had to be provided for the very first time in the WSG. This was an important contribution to the essentials needed in order to set a standard for the formalization of Lusoga as a language of instruction.

The main shortcoming to the specification of this information in Lusoga is that since Nabirye (2008) was an academic study (in the form of an MA dissertation), the detailed discussions on how the specification process was carried out as well as the results are mainly treated in the study itself. Some of the results are therefore merely 'used' in the WSG, with no explanation on how the conclusions were arrived at. Other results, although obtained through the same research process, were considered too new and needed further consideration before being adopted, so those were only 'mentioned' in the WSG. As such, the WSG did not include entries and definitions for all the newly-specified Lusoga language terminology. All grammatical and linguistic data accrued from the research process is only summarily interspersed throughout the WSG, with the main objective of attaining lexicographical goals.

The intended user of the WSG was assumed to have attained some formal 
grounding and to have the ability to read and understand the information in the WSG. Though the elementary school category was not directly addressed, it now turns out that this group most urgently needs to use the WSG. Yet this user category needs more assistance on how to decode data in the WSG. A new and more focused presentation style of the WSG information is therefore in order to address the new target audience.

\section{Mother-tongue education in Uganda}

After the Ugandan Parliament passed the teaching of nine regional indigenous languages of Uganda as a medium of instruction in lower primary, the implementation of this language policy was passed on to the National Curriculum Development Centre (NCDC). In the period 2005-2006, the NCDC embarked on the development of the so-called 'thematic curriculum' and syllabus for the teaching in the mother tongue in primary 1-3, which was passed in July 2006 by the Minister of Education and Sports, to be implemented starting in February 2007 (NCDC 2006: 1). The thematic curriculum and syllabus was piloted in the districts of Kampala, Rakai, Rukungiri, Kasese, Kabarole, Arua, Gulu, Moroto, Kumi, Iganga, and Nakasongola (NCDC 2006: 1). The pilot districts were chosen on the basis of their coverage of the nine regional indigenous languages that met the conditions for approval.

During the testing stage, however, it was observed that teachers in most of the regional indigenous languages were not using those languages in instruction, even though they were time-tabled. Another observation was that the teachers supposed to teach these languages were instructed and trained in methodologies for teaching foreign languages, and lack the right methodology and know-how for the formal instruction of indigenous languages. Moreover, the teachers themselves do not know the indigenous languages fully. Even though they may be good speakers, they cannot read or write or ably teach the indigenous languages. It was noted that this is further hampered by the fact that some of the languages, amongst them Lusoga, largely exist orally and are not documented. Instructional materials like dictionaries, textbooks and readers are lacking.

\subsection{Lusoga as a medium of instruction in primary 1-3}

In Busoga, the pilot initiative of teaching in Lusoga was carried out in the districts of Iganga and Namutumba, in fifteen primary 1-3 schools (CRC and CCFU 2008: 1). In late 2006 and early 2007, the Cultural Research Centre (CRC), with the financial and technical support from the Cross-Cultural Foundation of Uganda (CCFU), carried out research in these districts to gauge the impact of the introduction of Lusoga as a medium of instruction in lower primary classes. The main advantage noted in this pilot was that there was improved perform- 
ance and student participation in class activities. There also was a noted renewed sense of self-value.

However, the CRC observed that sustainability of the indigenous-language teaching programme had many challenges, mainly because teachers had a relaxed attitude towards the teaching in and of Lusoga which was regarded as meant for the poor and boring. Also, Luganda and English were preferred as language subjects because they are formalized and are easier to teach when compared to Lusoga. The latter is of course due to the lack of reference materials and a formalized foundation for the teaching of Lusoga, which raises scepticism as to the success of the language policy in the region.

\subsection{Lusoga as a subject in senior $1-4$}

The NCDC language-teaching syllabus for the ordinary $(\mathrm{O})$ level of secondary school (i.e. senior 1-4) focuses on the teaching of vocabulary, language structure, and language skills. In the case of Lusoga, a monolingual dictionary of Lusoga to facilitate the learning of Lusoga vocabulary is now available, namely the WSG. However, the references for teaching the Lusoga language structure are not yet available. Also, the readers to enable a good grounding in the learning and practice of more advanced grammar and different language skills are limited to story book primers (i.e. those mentioned in the fourth category of Lusoga references) and informal oral literature. Therefore, while the NCDC thematic syllabus has a provision for the teaching and examination of a grammar component, with respective descriptions of the teaching content at every level (NCDC 2003: 9-43), the teaching of Lusoga grammar lacks the very foundational requirements - that is standard grammar texts - to successfully carry out this aim.

\subsection{Escaping the conundrum}

Sections 4.1 and 4.2 sketched a grim picture: Teachers in lower primary typically obtained senior 4, yet those teachers were not given the tools to teach the regional indigenous languages (cf. §4.2), while the lower primary pupils do not have any material to study those regional indigenous languages either (cf. §4.1). Notwithstanding these problems, Lusoga is currently being 'used' as a medium of instruction in lower primary. Monolingual literature to serve as references is thus urgently required, and the NCDC is outsourcing for assistance to further the goal of teaching mother tongues in Uganda. It is an understatement to say that the NCDC is facing problems with the implementation of this goal, and it will not surprise anyone that they have called on studies like the WSG to assist in guiding the process of mother-tongue education in the Busoga region - and hoping for similar studies to emerge for the other regions. 


\section{The new target audience for the WSG}

There are two kinds of users who have emerged from the findings of the NCDC pilot studies, namely the primary 1-3 pupil and his/her teacher (who typically reached senior 4 ).

The first user is the primary 1-3 pupil whose education system for the first three years is conducted entirely in Lusoga. This is an elementary user who is just being introduced to the formal education system. This user is fully monolingual, especially if not raised in an urban setting. $\mathrm{He} /$ she is just learning how to read and write and has no prior knowledge of the structure of languages. This user is also still in the process of mastering the mother tongue and needs a lot of practice in order to acquire the language in all its facets.

The second user is the primary Lusoga language teacher who is supposed to use Lusoga as the medium of instruction in primary 1-3 and as a subject in primary 4-7. The teacher in this category has only attained senior 4 . He/she was trained to teach the English language and other subjects in English in primary education, but not to teach Lusoga, nor in Lusoga. This teacher has the innate structure of Lusoga which he/she displays orally but has most probably never read or written in Lusoga at all. He/she can be assumed to have good oral skills of the mother tongue but does not formally know the rules of the language he/she speaks.

From the 1950s up until the early 1980s, there was a provision for mothertongue education in each region. Students in the Busoga region would in this instance have learned the structure of Luganda (not Lusoga!), and how to read and write it, but that provision is no longer available. For our current teacher, teaching Lusoga is boring because there is nothing extra he/she can add to the formalized mother-tongue education system other than correcting mistakes noted in speech with rules he/she has internalized but cannot explain.

Given this state of affairs the teacher and the pupil are just as 'clueless' with regard to the structure of Lusoga that they both need assistance. Presently, this teacher has resorted to recounting traditional stories in the Lusoga lessons, with no reference to the relevant structural language content. Although oral literature, which is acquired informally, can inform some teaching tasks, at the moment it lacks the formalized structure needed to facilitate the learning of Lusoga language rules. In the long run, the stories run out and the subject becomes boring to teach for the teacher, boring to learn for the pupil, and is consequently abandoned as shown in the findings of the pilot study.

The nature of the user in the elementary category is delicate. These pupils mainly learn Lusoga from informal settings where no formal structure is stipulated. Although teachers of these pupils are mature, they too lack the formal training needed to understand the Lusoga language structure and the right teaching methods to pass it on to their pupils. The teachers do not (yet) know how to decode the information in the highly-specialized academic studies listed in the second and third categories of Lusoga references. They may also 
fail to comprehend or even apply the information in the WSG for their teaching purposes. In addition, one should of course also keep in mind the very real possibility that they have hardly had any exposure to dictionaries in their lives, dictionaries in any languages, and that they do not know how dictionary information could inform their teaching tasks.

In this context both the pupil and the teacher need guidance on the structure of Lusoga. The teacher needs assistance and training on what the structure of Lusoga entails before he/she can teach. He/she is most likely to benefit from the dictionary data in the WSG and by doing so improve his/her formal knowledge of Lusoga. This teacher can be guided further on the linguistic data given to enable him/her to develop a syllabus or lesson plan with the data given in the dictionary. Success of this assumption is based on the kind of information provided in the Guide to help direct the teacher's focus on the selection of topics to teach in each Lusoga lesson.

\section{The WSG and the development of language training materials}

In order to develop language training materials for schools in Uganda, the NCDC needs assurance that the literature in question has been prepared in accordance with the requirements set in their O-level syllabus (NCDC 2003). To understand the way in which the NCDC works, it is revealing to now briefly look at its dealings with the general public on the procuring of study materials for schools.

The Ministry of Education and Sports (MoES) in Uganda is charged with ensuring the success of the national language policy. The MoES mandates the NCDC to implement actions to be taken to ensure that the national language goals are met. The NCDC seeks the specialist help from institutions of higher learning, such as the Makerere Institute of Languages, Language Boards (these are presently instituted by the Constitution but not yet fully systematized nor functional), as well as any interested parties. Whenever necessary and on an ad-hoc basis, the NCDC also calls on religious organizations (e.g. the CRC), non-governmental organizations (e.g. the CCFU), teachers, researchers, and publishers. All of these have so far constituted the consultants on mothertongue education for the NCDC. Though some Ugandan languages are better documented than others and consequently have more reference materials than others, skilled personnel to implement mother-tongue education in all of the nine regional indigenous languages is still lacking.

Since the government is not offering funding to interested parties to invest in research or to train mother-tongue teachers and researchers, it is not surprising that the results from the pilot study conducted by the NCDC showed that there were gaps that may necessitate the revamping of the whole programme. This is the level at which adaptation of the WSG is being suggested to help in the teaching of Lusoga. The WSG was developed at an institution of higher learning and, in addition to the advantages and contributions already 
mentioned in this article, it was very well received by the general public. For a sample of the reactions to the arrival of the WSG - all unanimously positive see for example Aryatuha (2010), Ssejjengo (2009), Tendo (2010), Tumusiime (2010), or Wandera (2010).

\section{What is at stake for the WSG in this context?}

The language information in the WSG, though relatively basic, is not yet truly fitting as a teachers' guide. This information needs a new presentation style befitting primary school education. In this context, the primary teacher is the user who should be addressed. This is so because, at present, this teacher's needs are easier to address compared to the needs of his/her pupils. The teacher mainly needs assistance on how to develop a syllabus and lesson plans for teaching Lusoga, using the data that already exists in the WSG. The main goal in the remainder of this article is therefore to specify the relevant WSG information for this user, and to show how lessons can be drawn from it. For this teacher, two monolingual Lusoga references will eventually be availed, namely the Teachers' Guide and the WSG.

Though the results of the Nabirye (2008) study are undoubtedly a contribution to the study of Lusoga, they have their own shortcomings. Chiefly, not all findings from this study have so far been tested in full on the target audience. Although the way in which the WSG data is presented may seem prescriptive, directing users to 'the right way' Lusoga ought to be used, it is a compromise that lexicographers in this position have to contend with. Recall Zgusta's caution to lexicographers in this regard: "anticipate that [your decisions] will not be to everybody's liking and that the real development of the language itself may decide against [your] choice" (1971: 293). The specification and description of language information in the WSG was however based on a logical analysis, therefore any issues arising for or against the findings of the study are open to discussion.

The advantage, of course, is that procuring a proper testing measure for the WSG at this point in time, something initially thought to be a dream, could be born out of this process. Users will place more demands on the dictionary and strive to understand the information, so that hopefully more questions will arise about the WSG data. The new proposed Lusoga language terms now have a chance to be tested to see whether they are appropriate, adequate and understood by the target audience.

\section{The primary Teachers' Guide for the teaching of Lusoga}

At present, the authority of a Teachers' Guide is what the NCDC would like to have in order to consider the literature worthy of a reference for teaching Lusoga. The information specified for the Teacher's Guide and how it is to be presented is given in the sections that follow. ${ }^{6}$ 
It is important to note that the primary teacher training course does not restrict trainees to the teaching of certain sections only of the primary school system, thus either lower primary or upper primary. Consequently, although this article aims to address the teaching of Lusoga in lower primary, it will also specify Lusoga data for primary $4-7$ wherever applicable. In the upper primary level, Lusoga is taught as a subject in Lusoga (as is the case for lower primary), although the medium of instruction for everything else is English. Coverage of information necessary for the teaching of Lusoga in the entire primary section helps the primary teacher to get an overall orientation on how to conduct Lusoga lessons in whichever level he/she ends up teaching.

The subsections that follow summarize topics to be covered based on the information given in the central section of the dictionary, the extra-matter texts, as well as the Language Portrait found in the WSG. These topics include the orthography, pictorial illustrations, word categories, the counting system, quantification and measuring, usage labelling, a language portrait, and a glossary of terms. A summary of the contents in each section is given with sample references on how the topics can be actualized in a lesson.

\subsection{The orthography}

In this section, reference will be made to Namyalo et al. (2008) because it is now the orthography approved by the NCDC as the standard for writing Lusoga. A detailed specification of the new alphabet and the reasons why earlier studies have deviated from this should be covered. This discussion will be based on the justifications found in the WSG. For example, letter ' $\mathrm{C}$ ' featured in the WSG alphabet to host abbreviations, but is not used otherwise in Lusoga. Letter ' $\mathrm{J}$ ' was also introduced to cite foreign words that have entered into Lusoga and are now in standard usage, such as Jinja (a major town in the Busoga Kingdom, as well as the name of the district around it). Letter ' $R$ ' was dropped from the Lusoga orthography based on the argument that it is not the sound rendered in speech by the Basoga; it was only maintained in the WSG to cater for abbreviations. Clarification of this nature is of importance to the teacher and aims to show that the alphabet can be dynamic and altered with justifications to serve specific purposes as was the case in the WSG.

Teaching the rules of writing should be introduced in lower primary. This can be achieved by teaching the writing of single, double, and triple letters first. Exercises testing pupils on words with contrastive spellings, or thus for example those having short vs. long sounds, can also help the teaching of the letters used in the Lusoga alphabet. After that the focus should be on the teaching of Lusoga spelling. Pupils can for example be asked to fill in missing parts of words or sentences not only to test their competence in writing, but also to (implicitly) test their knowledge of morphology and vocabulary.

Teaching the composition of sentences and the right word order should also be introduced in lower primary. This will be coupled with teaching the use 
of the right punctuation marks within and at the end of sentences. A list of all the Lusoga terms for the punctuation marks is given in the Language Portrait of the WSG. Teaching of punctuation can actually be an independent lesson. The teaching of capitalization for proper nouns (personal names and place names) and for words at the start of sentences is also one of the ways to teach punctuation in lower primary. Exceptions to the rules of writing and sound changes can be introduced later, in upper primary, and given further attention in secondary school lessons of Lusoga to build on what was already learned.

Symbols used to write and represent linguistic information are given in the front matter of the WSG. All the symbols used also have their Lusoga terminology specified for the very first time in the WSG. Examples of symbols are punctuation marks, symbols for the formalized representation of linguistic information, symbols found on a keyboard, etc. The different types of symbols serve various tasks and may not all be important for the primary section. However, some are really vital like the punctuation marks which should be featured in relation to the proper writing of sentences. As pointed out, this is a subject that should be introduced in lower primary. A selection of the more advanced symbols for the formalized representation of linguistic information, such as phonetic symbols, may be introduced in lower primary too to teach the pronunciation of some letters of the alphabet and words with contrastive sounds. This can later be expanded in upper primary to introduce dictionary awareness as an integral part of language learning. Exercises at the upper primary level could involve studying what constitutes dictionary information and how to find words plus meanings in dictionaries.

The alphabet, rules of writing, pronunciation, punctuation, and dictionary use are subjects that can feature in primary lessons of Lusoga. All these subjects help in the teaching of the Lusoga orthography. The same subjects can then be expanded as the teacher wishes to teach specific language skills.

\subsection{Pictorial illustrations}

Throughout the WSG, there are hundreds of drawings - illustrating various single lemmas and bringing exponents of certain semantic fields together and these may be singled out. On the one hand such drawings can be used to mimic a picture dictionary, a type of dictionary that would otherwise be typical for lower primary users, and on the other hand these drawings can be used to develop lessons that revolve around vocabulary building. In both these scenarios, the links back to the lemmas in the central section of the dictionary itself should be kept in mind for upper primary, as doing so constitutes a gentle approach to creating a genuine dictionary culture.

For example, Addendum 6 shows the pictorial illustration found at the lemma egaali 'bicycle'. Not only is the object of the lemma itself depicted, but all the important parts of that object are named as well. Needless to say, all those parts have been included in the WSG as lemmas in their own right. 
As another example, Addendum 7 shows one of the eight full-page plates with illustrations included in the middle matter of the WSG, in this case for various modes of transport (not repeating those already covered at the lemmas themselves). Other onomasiological fields found in the WSG include fruit and vegetables, animals, insects, musical instruments, clothes, etc.

\subsection{Word categories}

Terms specified for the Lusoga word categories are given and exemplified in the front matter of the WSG. A description of the nature of information in each category is given but the terms are not defined in the dictionary. In the Teachers' Guide, therefore, the meaning and function of each term will be given and also treated in the glossary to be appended to the booklet. This will not only provide the first explanatory record for this type of information but also provide a testing ground for the new terms. If the proposed terms are easily understood by this audience then they can be adopted and passed as the standard Lusoga referents for word categories in future texts.

Characteristics of each word class can also be described in a series of lessons, some of them linked to the types of words shown in the pictorial illustrations (cf. \$8.2), for example to illustrate the difference between nouns and verbs. The depth of teaching this subject will depend on the level of the learner. In lower primary, for example, pupils may learn the regular noun classes and regular verbs with simple tenses. In upper primary, irregular forms of words can be introduced, with possibly links to rules for sound changes.

Word formation processes can also be introduced while teaching word classes, thus focusing on full word forms, affixes, tenses and compounds, plus the proper way in which all of these should be used and written. Exercises can be varied depending on the level of the learners.

\subsection{The counting system, quantification and measuring}

The Lusoga counting system, as in any other Bantu language, is both a highly familiar and linguistically interesting category to spend ample time on with young learners. Even just to count from one to ten, one already uses a number of different word classes and grammatical constructions, and these language processes can be seized on for teaching purposes, linking them to noun, adjective and verb bases, as well as to the wider grammar.

Quantifying and measuring items are two further fertile topics. The teaching of age ranges, for example, is useful to vocabulary-learning lessons. In such lessons pupils can be tasked to learn terms used to refer to people in given age groups from infancy to maturity. See Addendum 8. Lessons about days, times and time durations - see Addenda 9, 10, and 11 respectively - can all be used to test the writing skills of pupils, where they detail activities of their 
day. The teaching of weights (i.e. heavy vs. light; kilos, tonnes, etc.) can be used to dramatize language lessons with pupils acting out roles of selling commodities of different quantities and sizes.

Terms proposed for each of these quantification and measuring sequences will be listed in the glossary for easy reference. For those that were not already in the Lusoga system, new words were coined, and these will also have to be explained. Unlike the parts of speech, punctuation marks, and symbols, most of the terms for this category were already in the language but had not been given prominence. This is thus also one of the WSG types of data that still need to be tested. New or alternative terms not initially targeted in the WSG may arise out of this testing process and adopted in future references.

\subsection{Usage labelling}

A list of all the usage labels used in the WSG is given in its front matter. This data is also specified for the very first time in Lusoga but the form in which it is given in the WSG fits a more advanced user. The concept entailed in usage labelling can however be simplified and introduced in lower primary.

Exercises meant to teach usage in lower primary could focus the teaching on how sentences render emotional effects (i.e. surprise, anger, pity, etc.). In upper primary, teaching of usage could for example focus on the writing of formal vs. informal letters - examples of which are also included in the WSG middle-matter texts. Treatment of the different writing styles is a good exercise to test pupils on how to write and on how to use words properly.

Usage-labelling information can also help to test the writing and speaking skills, whereby pupils are asked to act out or write about different emotions. This exercise can help to build their vocabulary since they are tasked to choose the right words to bring about a desired emotional effect. Exercises on usage can therefore feature in lessons at different levels of education. For advanced learners this topic is essential, especially for those who would like to use Lusoga for special purposes. Lessons on usage can further be moulded depending on the level of learners and the intended objectives.

\subsection{A language portrait}

Addenda 8 to 11 are samples from the first two pages of the Language Portrait in the WSG. That section contains a full 15 pages (C1-C15), and is actually a goldmine of topics that can serve as starting points to build out the Teachers' Guide. Three more possible topics follow.

Gender information can for example help to explain how to differentiate between femininity and masculinity. Lessons on this subject can be featured in the teaching of parts of words where pupils are asked to mark the right prefixes that represent specific genders on names and titles. For instance, Is- is a 
masculine prefix mostly used at the beginning of titles, while Inh-is the feminine counterpart. Examples of such words are Isebantu 'King' and Inhebantu 'Queen'.

Names of colours in Lusoga can be taught in the study of adjectives and story writing, where pupils could be asked to write about their colour preferences or the colouring processes they have observed both in traditional and modern life (e.g. the dying of hair vs. the dying of palm leaves for making mats or clothes). Learning about working with colours could also be further developed in other subjects such as in the study of pollination or in art lessons where pupils learn how to shade.

Lastly, coverage of the family tree and the related terms can provide pupils with interesting ways to describe their families and their relations to different people in the family structure - either from the maternal or paternal side of the family. This information also forms a bridge between school activities and home activities. At this level the parents can also be involved in the learning of Lusoga and the Busoga culture.

\subsection{A glossary of terms}

The glossary will consist of the new Lusoga language terms and references to other Lusoga works. The terms included will inter alia cover grammar, word categories, usage labels, punctuation marks, symbols, quantification, and time measurement referents. These terms will have very short definitions. This is done in order to make the Guide available as an independent reference.

\section{Concluding remarks}

Coverage of the Lusoga orthography and word classes in particular are considered relevant and apt for learning in primary. In later school years, a pupil can build on the foundations given during this period to obtain a broader view of the language. Coverage of efficient language usage, the counting system, and other language-related issues are also considered essential and complimentary to the learning of the two main focus areas in primary-language education. For all these areas, the WSG already contains the necessary information, albeit in synthesised form, which is of course in line with lexicographical practice. Note that this does not necessarily mean that the data given in the WSG is comprehensive in that it already covers all topics required for primary-language education. Rather, the WSG is currently the only monolingual resource on Lusoga which contains such divergent types of information, and which can thus be targeted to assist in the teaching of Lusoga at the elementary level.

The subject of this article could of course also have been addressed by means of the production of two very specific forms of literature, namely a children's grammar and a children's dictionary, both designed and customised for 
the primary level. Such an approach was not suggested for the simple reason that the teaching of Lusoga is currently already being implemented, and such literature would thus be needed as of yesterday. Producing these new types of Lusoga teaching materials should of course be considered, but only in the knowledge that creating these materials from scratch will take a considerable amount of time. Moreover, funding for the national language policy is extremely poor at present, and most if not all of the documentations for mothertongue education are currently privately sponsored. For this reason, publishers and independent researchers who wish to make some financial gain in this market are very reluctant to forge forward. That is the main reason why we have chosen to capitalize on what is already available for Lusoga, namely the Eiwanika ly'Olusoga, and to empower this monolingual dictionary so it acquires a more divergent application than the one originally intended.

\section{Endnotes}

1. Uganda has a 13-year education cycle: seven years for primary (P) and six years for secondary (S). Each is divided into two levels, three years of lower primary (P1-P3) and four years of upper primary (P4-P7), followed by four years of ordinary "O" level (S1-S4) and two years of advanced "A" level (S5-S6). Learners drop out at any of these levels, with very few moving on to tertiary education.

2. Although Matovu and Walusimbi (2000) is listed here, the research referred to was abandoned, and the results remain unpublished.

3. This work incorporates the earlier BSU (1996), which in turn incorporates the even earlier BSU (1994).

4. On 8 February 2010, the Centre for Advanced Studies of African Society (CASAS) signed a memorandum of understanding with the National Curriculum Development Centre (NCDC) whereby the CASAS harmonized orthographies would henceforth form the NCDC basis for standardizing the entire mother-tongue writing system. As a result, the orthographies in Namyalo et al. (2008) have now become the standard for writing Luganda, Lusoga, Lumasaaba, Lusaamya, Lulamogi, and Lunyole. M. Nabirye was responsible for Lusoga.

5. For bilingual equivalents involving other Bantu languages - in dictionaries for Cilubà, Swahili, Northern Sotho and Zulu — see De Schryver (2008, 2008a, 2008b).

6. Although English is used in this article to summarize the items covered in the guide to the teaching of Lusoga, the Teachers' Guide itself will of course be written exclusively in Lusoga.

\section{References}

Aryatuha, M. 2010. Book Review: Eiwanika ly'Olusoga. Red Pepper, March 2010.

Babyale, S.C. 1999. Gulama w'Olusoga Omukalamu [The Proper Lusoga Grammar]. Unpublished B.A. Dissertation (written in English). Kampala: Makerere University.

BSU. 1994. Mariko. Omutwe Ogwokuna n'Ogwokutaanu mu Lusoga [A Selection from St. Mark's Gospel, Chapters 4 and 5, in Lusoga]. Kampala: The Bible Society of Uganda. 
BSU. 1996. Mariko Amawulire Amalungi mu Lusoga [The Gospel of Mark in Lusoga]. Kampala: The Bible Society of Uganda.

BSU. 1998. Endagaano Empyaka [The New Testament]. Kampala: The Bible Society of Uganda.

Byandala, G.I. 1963. The Lusoga Orthography. Iganga.

CRC. 1998. Kintu. Jinja: Cultural Research Centre.

CRC. 1999. Ababita Ababiri. Jinja: Cultural Research Centre.

CRC. 1999a. Akatabo Akasooka ak'Enfumo edh'Abasoga. Jinja: Cultural Research Centre.

CRC. 1999b. Amagezi Tigamalwayo. Jinja: Cultural Research Centre.

CRC. 1999c. Ensambo edh'Abasoga. Jinja: Cultural Research Centre.

CRC. 1999d. Mwidhe Tufume. Jinja: Cultural Research Centre.

CRC. 1999e. Obufunvu Magezi. Jinja: Cultural Research Centre.

CRC. 1999f. Omuvangano mu Busoga. Jinja: Cultural Research Centre.

CRC. 1999g. Twire ku Butaka. Jinja: Cultural Research Centre.

CRC. 2000. Enkabi n'Ekifiini mu Busoga. Jinja: Cultural Research Centre.

CRC. 2000a. Lwaki Abakazi Tibabeeda Mulambo. Jinja: Cultural Research Centre.

CRC. 2002. Ebikoiko eby'Abasoga. Jinja: Cultural Research Centre.

CRC. 2003. Ebindi kw'idembe ery'Obw'omuntu mu nsi Yoonayoona. Jinja: Cultural Research Centre.

CRC and CCFU. 2008. Reclaiming our Language through Education. Teaching in Lusoga in Primary Schools: What Change In and Out of the Classroom? Jinja: Cultural Research Centre \& Kampala: Cross-Cultural Foundation of Uganda.

De Schryver, G.-M. 2008. Why Does Africa Need Sinclair? International Journal of Lexicography 21(3): 267-291.

De Schryver, G.-M. 2008a. A New Way to Lemmatize Adjectives in a User-friendly Zulu-English Dictionary. Lexikos 18: 63-91.

De Schryver, G.-M. 2008b. The Lexicographic Treatment of Quantitative Pronouns in Zulu. Lexikos 18: $92-105$.

De Schryver, G.-M. and M. Nabirye. 2010. A Quantitative Analysis of the Morphology, Morphophonology and Semantic Import of the Lusoga Noun. Africana Linguistica 16: 1-45.

Gonza, R.K. 2007. Lusoga-English Dictionary and English-Lusoga Dictionary. (Revised edition of P. Korse's (1999a) dictionary.) Kampala: MK Publishers.

Kajolya, J.B.N. 1990. The Lusoga Orthography. (Revised edition of G.I. Byandala's (1963) Lusoga orthography.) Jinja: Lusoga Ecumenical Committee.

Korse, P. 1999. A Lusoga Grammar. (Two subsequent editions were published in 2000.) Jinja: Cultural Research Centre.

Korse, P. 1999a. Dictionary Lusoga-English/English-Lusoga. Jinja: Cultural Research Centre.

Ladefoged, P., R. Glick and C. Criper (with an introduction by C.H. Prator and additional material by L. Walusimbi). 1972. Language in Uganda. Ford Foundation Language Surveys 1. London: Oxford University Press.

LULANDA and CRC. 2004. Empandiika y'Olulimi Olusoga Enkalamu/Standard Lusoga Orthography. Jinja: Lusoga Language Authority.

Lyavala-Lwanga, E.J. 1967. Endheso dh'Abasoga. Kampala: Milton Obote Foundation.

Lyavala-Lwanga, E.J. 1969. Kiyini Kibi. Kampala: Milton Obote Foundation.

Matovu, C.N. 1992. A Synchronic Description of Lusoga in Terms of its Relatedness to Luganda. Unpublished Ph.D. Thesis. Kampala: Makerere University.

Matovu, K.B. and L. Walusimbi. 2000. A Linguistic Survey of the Current Status of the Dialects of Some Eastern Bantu Languages. Unpublished Manuscript. Kampala: Makerere University. 
Nabirye, M. 2008. Compilation of the Monolingual Lusoga Dictionary. Unpublished M.A. Dissertation. Kampala: Makerere University.

Nabirye, M. 2009. Eiwanika ly'Olusoga. Eiwanika ly'aboogezi b'Olusoga n'abo abenda okwega Olusoga [A Dictionary of Lusoga. For Speakers of Lusoga, and for Those Who Would Like to Learn Lusoga]. Kampala: Menha Publishers.

Nabirye, M. 2009a. Compiling the First Monolingual Lusoga Dictionary. Lexikos 19: 177-196.

Nabirye, M. 2009b. Dictionary Compilation for Mother-tongue Speakers of Bantu Languages. Zhu, R. (Ed.). 2009. Proceedings of the International Seminar on Kangxi Dictionary and Lexicology: 597607. Beijing: Beijing Normal University.

Namyalo, S., L. Walusimbi, G. Bukenya, M.W. Masakala, M. Nabirye and F. Kiingi. 2008. A Unified Standard Orthography of Eastern Interlacustrine Bantu Languages. Monograph Series 68. Cape Town: The Centre for Advanced Studies of African Society.

NCDC. 2003. The "O" Level Local Language Syllabus. Senior 1-Senior 4. Kampala: National Curriculum Development Centre.

NCDC. 2006. THEMA. The Newsletter of the Thematic Primary Curriculum. Issue 1. August 2006. Kampala: National Curriculum Development Centre.

NCDC. 2006a. THEMA News Letter. Issue 2. December 2006. Kampala: National Curriculum Development Centre.

Schoenbrun, D.L. 1997. The Historical Reconstruction of Great Lakes Bantu Cultural Vocabulary: Etymologies and Distributions. Sprache und Geschichte in Afrika, Supplement 9. Cologne: Rüdiger Köppe.

Ssejjengo, E. 2009. Books: Poetry Ruled. The New Vision, 31 December 2009.

Steeman, S. 2001. Kintu: An Annotated Edition of a Lusoga Play. Unpublished M.A. Dissertation (being a linguistically annotated version of CRC (1998)). Leyden: Leyden University.

Tendo, S. 2010. Book Review: Lusoga Gets Dictionary. Saturday Monitor, 6 February 2010, p. 22.

Tucker, A.N. and M.A. Bryan. 1957. Linguistic Survey of the Northern Bantu Borderland, Volume 4: Languages of the Eastern Section, Great Lakes to Indian Ocean. Published for the International African Institute. London: Oxford University Press.

Tumusiime, D. 2010. Lusoga Dictionary Printed. The Observer, 3 March 2010, p. 23.

UBS. 2006. The 2002 Uganda Population and Housing Census, Analytical Report, Population Composition. Kampala: Uganda Bureau of Statistics.

Van der Wal, J. 2004. Lusoga Phonology. Unpublished M.A. Dissertation. Leyden: Leyden University.

Wambi, M. and R. Naigaga. 2005. Idha Tusome [Come and We Read]. Jinja: Lusoga Language Authority.

Wandera, S. 2010. Dictionaries in 3 Local Languages Out. Daily Monitor, 22 February 2010, p. 13.

湯川，恭敏 [Yukawa, Yasutoshi]. 2000. ソガ語動詞アクセント試論 [Soga-go dooshi akusento shiron / A Tentative Tonal Analysis of Soga Verbs]. Journal of Asian and African Studies 60: 249290.

Zgusta, L. 1971. Manual of Lexicography. Janua Linguarum, Series Maior 39. Prague: Academia / The Hague: Mouton. 
Addendum 1: "Key to dictionary" in Gonza (2007: vi)

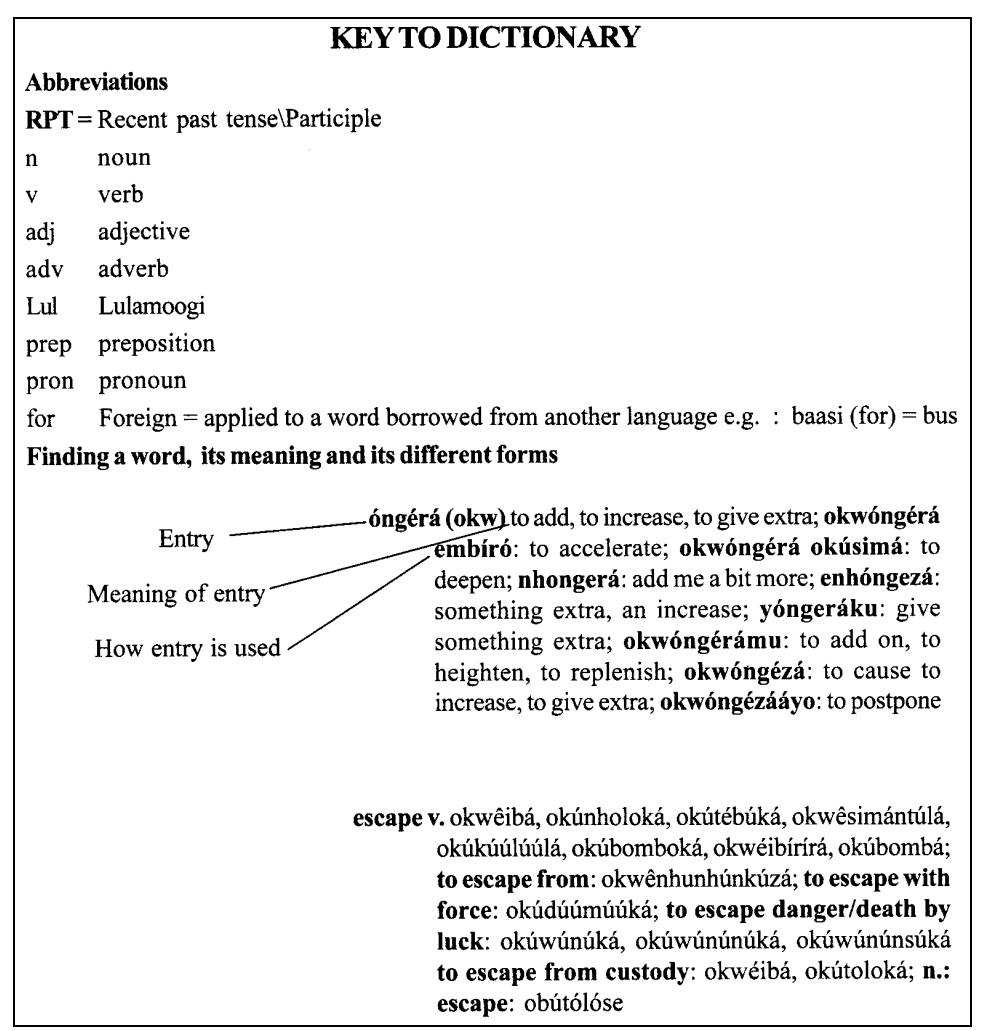

Addendum 2: Sample from the Lusoga to English side of Gonza (2007: 123)

\begin{tabular}{|c|c|}
\hline $\begin{array}{l}\text { lúfúmó (o) parable, story, fable, metaphor, narrative, } \\
\text { legend, myth, folk tale, fiction, pl. enfúmó; v.: } \\
\text { okúfúmá: to tell stories }\end{array}$ & $\begin{array}{l}\text { lúgéró (o) story, byword, illustration, legend, maxim, } \\
\text { metaphor, myth, proverb, a lie, tale; olúgéró } \\
\text { ólwégésa: allegory }\end{array}$ \\
\hline lúfúng $\delta(0)$ loincloth & lúgérógéró (o) kind of tree \\
\hline lúfúnhíró (o) a crease & lúgézi (o) sweat, perspiration \\
\hline $\begin{array}{l}\text { lúfútúbé (o) multitude of people = éíkúúkúubirá } \\
\text { lúgá (o) a cane, club, walking stick = omwigó, } \\
\text { whip }\end{array}$ & $\begin{array}{l}\text { lúgháánhi (o) strychnia plant used for fencing } \\
\text { (Dracoena fragrans, class: Agacaceae) } \\
\text { olúghánó }\end{array}$ \\
\hline $\begin{array}{l}\text { lugá (okú) to be unsettled, to move to and fro due } \\
\text { to some pressure, to wander around }\end{array}$ & $\begin{array}{l}\text { lúghaghá }(0) \text { wing } \\
\text { lúghágála }(0) \text { sharpener }\end{array}$ \\
\hline $\begin{array}{l}\text { lugaalúgá (okú) to be unsettled, unstable, to } \\
\text { dote on } \\
\text { lúgáátá (o) boasting = olúnkulú } \\
\text { lugabíre rubber sandle } \\
\text { lúgadá (o) reed pl. éngadá }\end{array}$ & $\begin{array}{l}\text { Lughálálírá the one who is aggressive (nickname) } \\
\text { lúgháló (o) a task, term of office, tum, shift, public } \\
\text { labour = olúghánó; okúkolá olúgháló: to take } \\
\text { your turn; okúkolá mu mpáló: to do it in tums, } \\
\text { to do in rotation, to rotate }\end{array}$ \\
\hline $\begin{array}{l}\text { lúgágáva (o) severe chronic illness, marasmus, } \\
\text { severe malnutrition in children, severe }\end{array}$ & $\begin{array}{l}\text { lúghangá (o) skull } \\
\text { lúgháyó (o) a conversation, chat, discourse = } \\
\text { ekíbonó, olúwáyó }\end{array}$ \\
\hline
\end{tabular}


Addendum 3: Sample from the English to Lusoga side of Gonza (2007: 325)

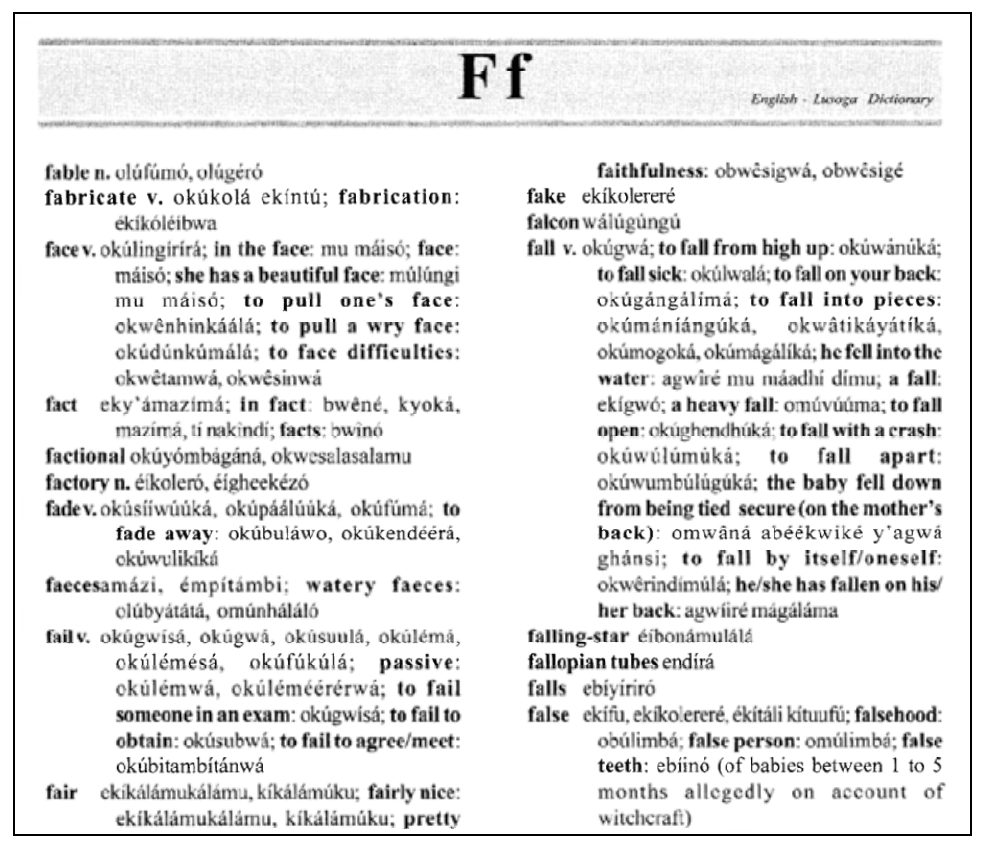

Addendum 4: Sample from the front matter in the WSG (Nabirye 2009: 616) [Note that the front matter was translated into English and included as a back-matter text in the WSG. The section shown here was taken from the back matter.]

\begin{tabular}{|l|l|l|l|}
\hline$l$ & liina & "noun" \\
$L$ & ekilanda & "transitive" \\
$l a z$ & omulazi & "demonstrative" \\
$m$ & nambeela & "adjective" \\
$n$ & nangeli & "adverb" \\
$n h i t v$ & obunhinhitivu & "intensifier" \\
$s k$ & ekisoko & "idiom" \\
$T$ & ekitalanda & "intransitive" \\
$t$ & nantabila & ekitobeko \\
$t b k$ & akawango & "auxiliary verb" \\
$w$ & obuweile & "variant" \\
weile & kyakuwulila & "affix" \\
wulil & nakayunzi & "past tense" \\
$y$ & "onomatopoeic" \\
\hline
\end{tabular}


Addendum 5: Sample from the WSG (Nabirye 2009: 467)

\begin{tabular}{|c|c|}
\hline 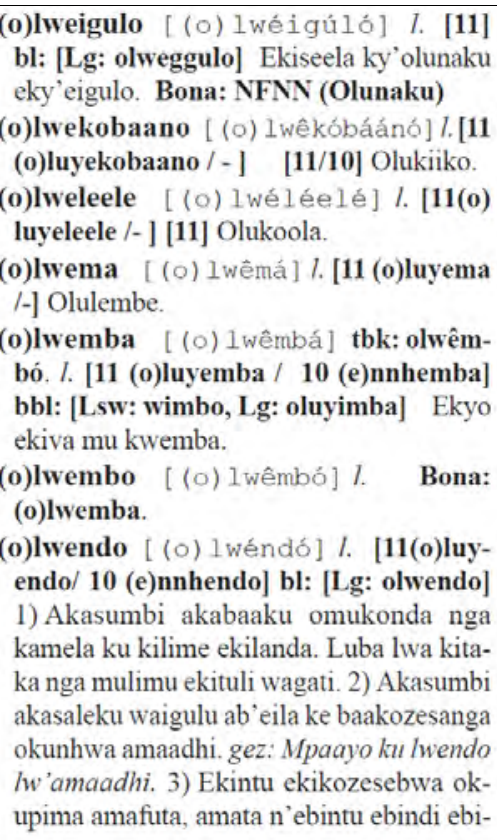 & 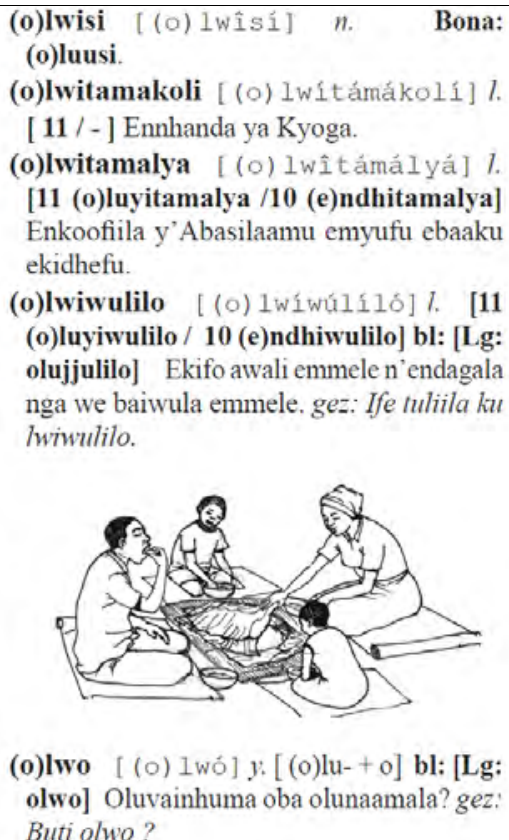 \\
\hline
\end{tabular}

Addendum 6: Illustration at the lemma egaali 'bicycle' in Nabirye (2009: 45)

\section{EGAALI}

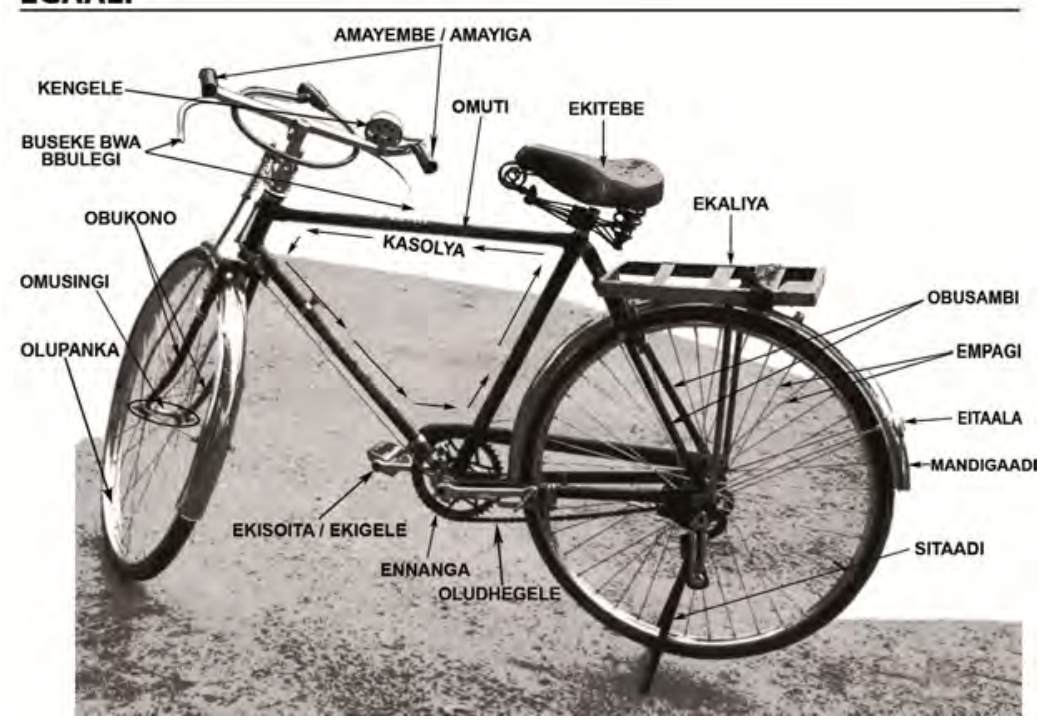


Addendum 7: Transport modes, from the middle matter in Nabirye (2009: D7)

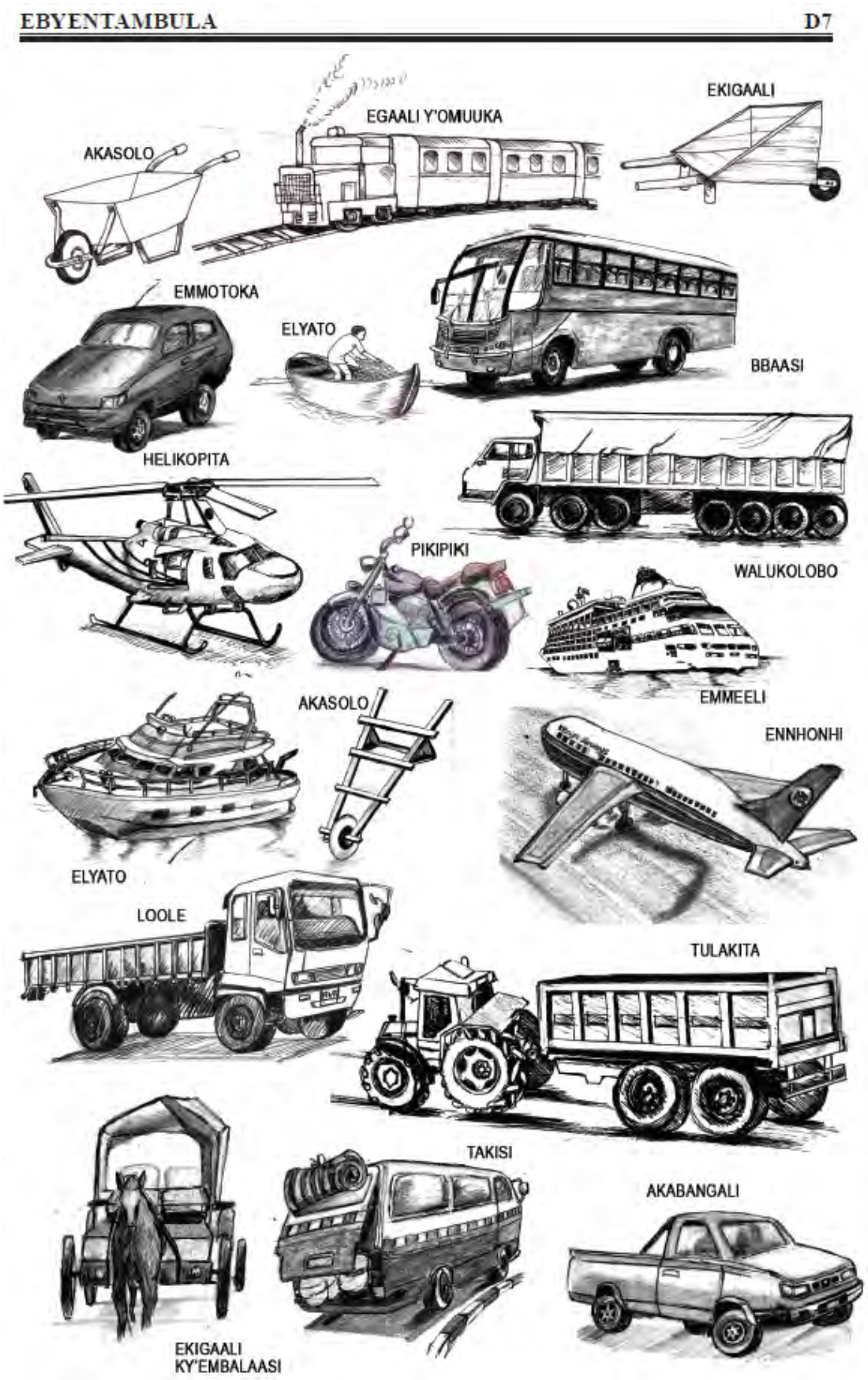


Addendum 8: Age ranges, from the middle matter in Nabirye (2009: C1)

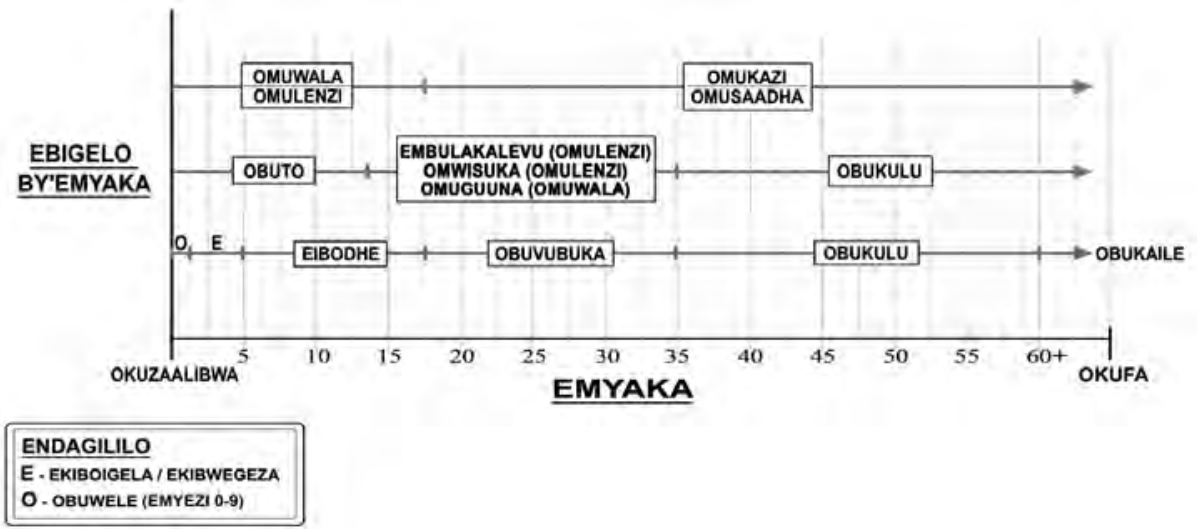

Addendum 9: Days in a month, from the middle matter in Nabirye (2009: C2)

\begin{tabular}{|c|c|c|c|c|c|c|}
\hline BBALAAZA & OLWokuBa! & OLWOKusatu & OLWOKUNA & OLWOKUTAANU & OLWOMUKAAGA & $\begin{array}{l}\text { SMABBiTIII } \\
\text { SAASILA }\end{array}$ \\
\hline $\begin{array}{c}\text { I } \\
\text { olveareatre }\end{array}$ & 2 & 3 & 4 & 5 & 6 & 7 \\
\hline $\begin{array}{c}8 \\
\text { ABNAZA } \\
\text { EMABTA }\end{array}$ & $\begin{array}{c}9 \\
\begin{array}{c}\text { OWOWERI } \\
\text { OLNABTA }\end{array}\end{array}$ & $\begin{array}{c}10 \\
\text { OWVOWUATU } \\
\text { OWharTA }\end{array}$ & $\begin{array}{c}11 \\
\text { OWOKUNA } \\
\text { OLWABITA }\end{array}$ & $\begin{array}{c}12 \\
\text { OLWOKUAANU } \\
\text { OLWABTA }\end{array}$ & $\begin{array}{c}13 \\
\text { OWOMLALAGA } \\
\text { OLWABITA }\end{array}$ & 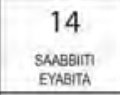 \\
\hline 15 & $\begin{array}{c}16 \\
\text { Eloulo: } 1 \text { DHo }\end{array}$ & $\underbrace{17)}_{\text {IEAO }}$ & $\begin{array}{c}18 \\
\text { ENronitoho }\end{array}$ & $\begin{array}{c}19 \\
\text { DhuUarilule }\end{array}$ & 20 & 21 \\
\hline $\begin{array}{c}22 \\
\text { BEALLZA EOHA }\end{array}$ & $\begin{array}{c}23 \\
\text { OWNOKUBLI } \\
\text { OLWOHA }\end{array}$ & $\begin{array}{c}24 \\
\text { OWNOKUSATU } \\
\text { OLWDHA }\end{array}$ & $\begin{array}{c}25 \\
\text { OWOKUNA } \\
\text { OLWDHA }\end{array}$ & $\begin{array}{c}26 \\
\text { OLWOKUTAANS } \\
\text { OLWIDAA } \\
\end{array}$ & $\begin{array}{c}27 \\
\text { OWNOMUNABCA } \\
\text { OLWDOHA }\end{array}$ & $\begin{array}{c}28 \\
\text { SAABBMIIIOHA }\end{array}$ \\
\hline 29 & 30 & 31 & & & & \\
\hline
\end{tabular}

Addendum 10: Day periods, from the middle matter in Nabirye (2009: C2)

\begin{tabular}{|c|c|c|c|c|c|c|}
\hline ESAAWA & $\begin{array}{c}(7: 00-11: 59) \\
\text { AM }\end{array}$ & $12: 00$ & $\begin{array}{c}(12: 01-4: 30) \\
\text { PM }\end{array}$ & $\begin{array}{c}(4: 31-7: 00) \\
\text { PM }\end{array}$ & $7: 01$ PM - 5:30AM & $\begin{array}{c}(5: 31-6: 59) \\
\text { AM }\end{array}$ \\
\hline $\begin{array}{c}\text { EKIGAMBO } \\
\text { KYE'KISEELA }\end{array}$ & ENYYO & EMISANA & EIGULO & DQWLE & $\begin{array}{c}\text { MADHAMBUUKA } \\
\text { / PWIPWIFWI }\end{array}$ \\
\hline
\end{tabular}

Addendum 11: Time periods, from the middle matter in Nabirye (2009: C2)

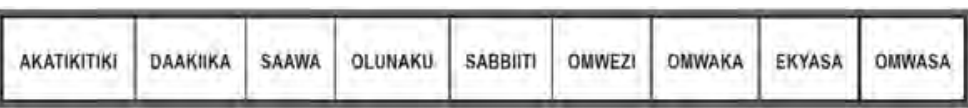

